Original Article

\title{
Awareness of Medication Error, Medication Management and Prevention among Staff Nurses in IMS \&Sum Hospital, Odisha
}

\author{
Sailabala Mohanty \\ Assistant Professor, Faculty of Nursing, S'O'A University,k-8, Kalinga nagar, Bhubaneswar, Odisha-751003
}

*Corresponding Author : Sailabala Mohanty, Assistant Professor, Faculty of Nursing, SUM Nursing College, SOA University, Bhubaneswar, Odisha - 751 003. M obile : +919439449891 E-mail : sailabalamohanty@ soauniversity.ac.in.

Received : : 17.10 .2015

Review Completed : 31.08.2016

Accepted

: 27.09.2016

Keywords : Medication error, nurse's knowledge on medication error, prevention of medication error.

\begin{tabular}{|c|}
\hline Access this article online \\
\hline Quick Response Code \\
\hline
\end{tabular}

\author{
Abstract \\ Aims : The study aimed to assess the knowledge of staff nurses about medication error, \\ prevention of medication error and itsmanagement.
}

Background : Accomplishment of medical order and medication administration are the prominent part of nurse'sjob.

Methods : A descriptive approach was under taken and data was collected in the month of M arch and April, 2014, from 100 staff nurses of IM S\& SUM HOSPITAL.

Results : A significant proportion of staff nurses (39\%) believed that carefully reading of instruction and labeling of the drug before administrating can prevent medication error followed by heavy workload and high nurse/patient ratio(16\%) and insufficient work experience(11\%)dueto huge turnover were mostly cited by nurses to prevent medication error.

Conclusion : Medication administration is the basic function of nurse. So the nurses should be well equipped with skill and knowledge needed for error free medication.

Implications for nursing management : Error free medication administration process requiresa continuous educational initiative on medication error with regards to prevention of medication error and its reporting and the short-term course on medication error should be added in orientation class by every health care organization.

\section{Introduction}

Medication error is a globally prevalent problem which may lead to various disasters like therapeutic failure, adverse effect of drug, longer hospital stay as well as wastage of resources, even death. ${ }^{[1]}$ M edication error is the foremost hindrance in patient safety as ever increasing demand medical care, as population ages. Medication error is the third most leading cause of death in U.S and 440,000 patients die every year from avoidable medical error. ${ }^{(2)}$ Not even a single health care institution is immune to medication error. So every patient is vulnerable to at least one medication error every day. ${ }^{(2)}$ In the third world and modern era, it is very difficult to find out the accurate figure of medication error, due to lack of proper reporting system, lack of proper achieving as well as absence of proper data registration system. ${ }^{(3)}$ As per NCC MERP," medication error is preventable event that may cause or lead to inappropriate medication use or patient harm while the medication is in the control of the health care professional, patient, or consumer. Such events may be related to professional practice, health care products, procedures, and systems, including prescribing, order communication, product labeling, packaging, and nomenclature, compounding, dispensing, distribution, administration, education, monitoring, and use. "Medication error can occur in any setting, like from prescribing to popping of drug by the patient. The most common causes of medication errors are bad hand writing practice of prescriber, abbreviations, drug delivery and stocking problems, lack of pharmacological knowledge of nurses, improper drug distribution, preparation error wrong administration, lack of proper instruction to the patient and lack of awareness of patient. ${ }^{(3,4)}$ Nurses are the backbone of patient care as they are directly involved in activities related to patient care. So nurses are the well positioned compared to other care providers to detect, 
report and prevent medication error. ${ }^{(5,6)}$ Various type of medication errors are found in every health setting ranging from prescription error to clerical error and $70 \%$ of total errors are found to be prescription error only. Error rates varied from $7.1 \%$ to $90.5 \%$ for prescribing and from $9.4 \%$ to $80 \%$ for administration. The most common types of prescribing errors reported were incorrect dose (with an incidence rate from $0.15 \%$ to $34.8 \%$ of prescriptions), wrong frequency and wrong strength. Computerized physician order entry and clinical pharmacist input were the main interventions evaluated. Poor knowledge of medicines was identified as a contributory factor for errors by both doctors (prescribers) and nurses (when administering drugs). ${ }^{(23)}$

The underlying reasons of medication errors are often undiagnosed but situational analysis shows that the leading causes of medication error encompass clogging of health care professionals with huge number of patients because of alarming shortage of health-care professionals, especially in developing countries like India. ${ }^{(5,7)} \mathrm{M}$ ohammad Al conducted a study on Jordan nurses' perspective about medication error reveal that wrong dose(26.2\%) and wrong patient(26.2\%) were the major types of medication error. The highest medication mishap is caused by the nurses, physicians and pharmacists are evident in the obtained figure at $48.4 \%, 31.7 \%$ and $11.1 \%$ respectively. In addition, heavy workload is the highest cause of medication errors at $41.4 \%$, reported by the nurses and $20.6 \%$ were due to the new staff. Ignorance of nurses with patient condition (1.6\%) was the lowest contributing factor of medication errors. ${ }^{(8)}$ Fu-in Tang ET. Al carried out a study on nurses related to the contributing factors involved in medication error showed that $76.4 \%$ nurses suggested that several factors were responsible for medication error. From the eight categories personal negligence $(86.1 \%)$, heavy workload $(37.5 \%)$ and new staff $(37.5 \%)$ were the three leading factors of medication error. The errors are mainly incorrect drug (26.4\%) and incorrect dose (36.1\%) and the two topmost error prone places are medical ward and intensive care unit respectively at $36.1 \%$ and $33.3 \%$. ${ }^{(9)}$ Seyyedah R. E. et al conducted a study on medication errors of nurses in the emergency department revealed that most common cause of medication mishaps were $48.93 \%$ due to abbreviated drugs name, $27.65 \%$ for insufficient pharmacological knowledge of nurses and $19.14 \%$ from massive work load. ${ }^{(10}$ The principal reasons of medication errors were found to be insufficient pharmacological knowledge, lack of drug administration skills and proper attitude of nurses. Zayed et al (2013) reported that $5.41 \%$ medication error occurred due to improper in following prescription and poor skill of drug administration. ${ }^{(24)} \mathrm{As}$ per $M$. Eric et al lack of pharmacological knowledge, poor skill, communication failure and failure to follow the prescription are the crucial causes of medication errors. ${ }^{(25)}$ Determining the causes and sources of errors is the prime step to prevent errors.As researcher wasfaced this issue inclinical observations, researcher decided to evaluate the knowledge of nurses about the causes and prevention of medication errors.

\section{Materials and Methods}

The descriptive survey approach was undertaken for the present study. The setting of the study was IMS \& SUM HOSPITAL. The samples were 100 staff nurses choose by probability random sampling technique from various wards. The inclusion criteria for samples were they mustpossess RN, RM number, at least worked for the last 6 months in the same ward and available during the data collection procedures. Prior permission was taken from hospital authority before data collection and written consent was obtained from the participants and assured about the non- disclosure of data. A structured questionnaire was developed by the researcher, based on MAEs (Medical Administration Error) reporting questionnaire by Wakefield et al and extensive literature review. The structured questionnaire was validated by 7 expert from various nursing colleges. The reliability score was 0.72 , which implies that the questionnaire was reliable. The questionnaire comprised of two sections and one section gathered data about socio-demographic variables like age, gender, marital status, religion, qualification and years of experience etc. The other section divided into 3 sub-sections, named as medication error, 
prevention of medication error and management of medication error comprising $21,14 \& 5$ items respectively. Each items had four options with only one appropriate answer scored as " 1 " and wrong one was " 0 ".

\section{Data Analysis}

Data was collected, coded, and entered in SPSS version 17.0 and subjected to statistical analysis.

\section{Results}

Table-1 represents the socio-demographic characteristics of subjects. The highest percentage (40\%) of staff nurses were in the age of 20-22 years, whereas only (35\%) were in the age group of $23-25$ years. ( $15 \%$ ) were in 26-28yrs age group, (10\%) were >28yrs age group. Hence, it is interpreted that most staff nurses in the study were young adults, this might be because of fresher's recruitment in hospital. Percentage wise distributions of staff nurses as per gender revealed that highest percentages (95\%) were female, whereas only (5\%) were male. Majority of the samples were unmarried $(53 \%), 38 \%$ were married, whereas $5 \%$ were divorced and $5 \%$ were widows. Most (45\%) people had been educated in GNM, whereas 43\% were B.Sc. (N) and $22 \%$ were Post Basic B.Sc. (N).With respect to years of experience, $43 \%$ nurses were under $0-1$ year of experience, whereas $27 \%$ were under $1-3$ years and above 3 years' experience were $30 \%$.

In Table-2 it has been found to be good knowledge in 67.6\% and $33.4 \%$ in average knowledge of the total respondents and no samples under poor knowledge. Thus it was conveyed that none of the staff nurse had poor knowledge and almost they had good knowledge about medication error and its prevention. According to the findings the mean and SD of knowledge scores of staff nurses were $(16.1 \pm 1.18)$ in the area "medication management" and "medication error" (10.37+1.53) with mean percentage (74\%) revealing good knowledge. However the lowest mean score was obtained by the staff nurses for "prevention of medication error" $(3.3 \pm 0.8)$ hence it represented average knowledge of staff nurses regarding how to avoid or prevent medication mishap.
A significant proportion of staff nurses(39\%)believed that careful reading of instruction and labeling of the drug before administrating can prevent medication error followed by heavy workload and high nurse/patient ratio(16\%) and insufficient work experience(11\%)due to huge turnover, were mostly cited by nurses to prevent medication error.(Figure-1)

There was no significant difference found between knowledge score and age ( $P \geq 0.22)$, gender $(P \geq 0.80)$, professional qualification $(P \geq 0.41)$ and years of experience $(P \geq 0.63)$ at a level of significance $(P<0.05)$.

Table 2 : M ean and Standard deviation of Knowledge of Nurses $n=100$

\begin{tabular}{|c|l|c|c|c|c|}
\hline SL NO & AREA & $\begin{array}{c}\text { MAX } \\
\text { SCORE }\end{array}$ & MEAN & SD & MEAN\% \\
\hline 1 & Medication management & 21 & 16.14 & 1.84 & 77 \\
\hline 2 & Medication error & 14 & 10.37 & 1.53 & 74 \\
\hline 3 & $\begin{array}{l}\text { Prevention of medication } \\
\text { error }\end{array}$ & 5 & 3.39 & 0.87 & 68 \\
\hline
\end{tabular}

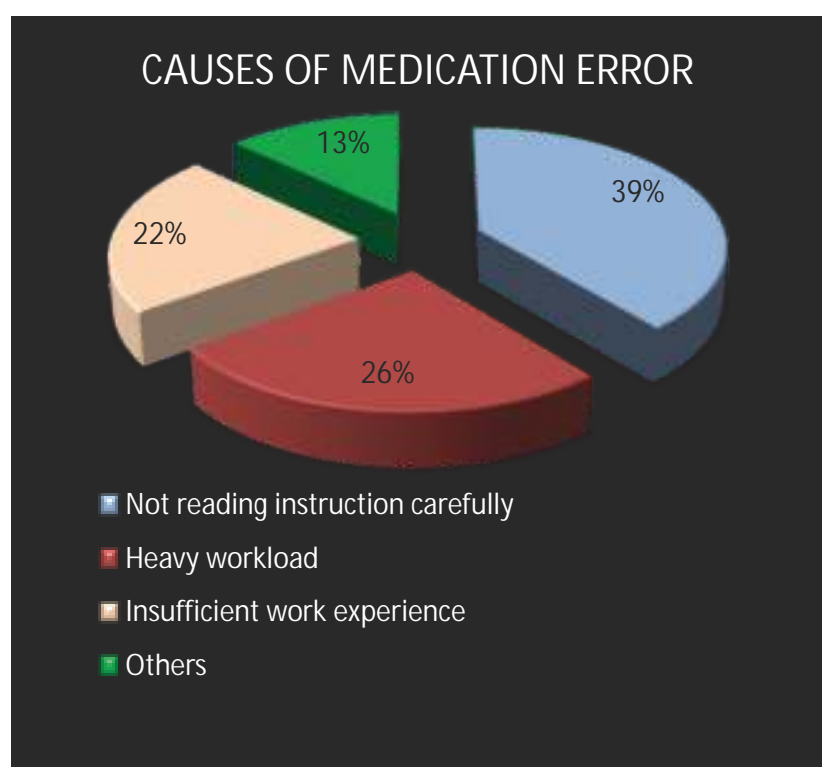

Figure 1 : Various causes of Medication error

\section{Discussion}

Medication error is the consequence of individual negligence to system failure leading to various disasters. The present study shows that most of the samples(67.6\%) are having good knowledge about medication error and $33.3 \%$ having average knowledge and none of the samples has low score. This finding is supported by a study 
conducted by Horiatiset.al (2013) who found that $54 \%$ samples were having medium score followed by $46 \%$ scored high, whereas no one had low score. ${ }^{(11)}$

According to findings of the study most of the nurses (39\%) reported that careful reading and following the instruction before drug administration can prevent the medication error to a great extent. A. Shasrhokhi et al reported in their study that the elite cause of medication error (98.7\%) caused by the nurses' inadequate attention during medication procedure as per the instruction manual. ${ }^{(21)}$

Heavy workload and high nurse/patient ratio is also a leading factor of medication error citied by $16 \%$ nurses. DM Olds and SP Clarke (2010) suggested that 40 hours or more per week have an increased likelihood to have needle stick injury and medication error particularly wrong dose administration ${ }^{(14)}$. Many other research findings also referred that tiredness and fatigue are the leading causes of medication error ${ }^{(10,11,14,15)}$. Existence of many other irrelevant works which the nurse has to handle along with over-crowded wards generate excess work load, unnecessary stress, increased responsibility among nurses, which is recognized as a prime factor for increasing incidence of medication errors. ${ }^{(11,12,13,18)}$

The present study reveals that fresher and insufficient work experience is the third most leading cause of medication error and suggested by other researches also. $\left.{ }^{(11,14,16,17)}\right)$. Johnson and M. Thomas(2013) reported that

\section{References}

1. James, T John, A new evidence based estimate of patient harms associated with hospital care: Journal of Patient Safety,2013;9:122128.

2. Patel I, Balkrishnan R. Medication error management around the globe: An overview: Indian Journal of Pharmaceutical Sciences, 2010; 72:539-545.

3. C Mohammad Ali, M Human, M Esmaeil, E Syyedeb R. Types and causes of medication errors from nurse's view point: Iranian Journal of Nursing and M idwifery Research.2013;18: 228-231.

4. Academy of M anage Care Pharmacy

5. D Barbara. Nurses role in medication safety: Nursing 2015.2015; 45:110-115.

6. Malhotra K, Goyal M, Walia R, Aslam S. Medication errors: A preventable problem: Indian Journal of Clinical Practice.2012; 23:1721.

7. Sewal R K, Singh P K, Prakash A, Kumar B, M edhi B.A prospective study to evaluate awareness about medication errors amongst health-care personnel representing North, East, West regions of India: International Journal of Applied and Basic Medical Research.2014;4 years of experience act as a prevention for possible medication error. They reported that 35\% samples had 8 years of clinical experience presenting 14.25 mean knowledge score where as $22.9 \%$ in 4-6 years' experience presenting the mean score $14.89{ }^{(18)}$ Grandell-Neimi et.al reported continuous relationship of educational level, professional experience of nurses with medication errors. $^{(19)}$

As per the findings there was no significant association in between knowledge score and demographic variables of staff nurses. As per M. A. Cheragi et al there was no significant relationship seen in between the demography of nurses(age, sex, gender, working experience) with knowledge scores of nurses of contributing factors of medication errors $(\mathrm{P}>0.05){ }^{(22)}$

\section{Conclusion}

Medication error is a grave situation for any health professional, nurses, to a great extent. Through the study it has been concluded that the majority of awareness is present within the nursing group, yet the possibility of awareness in medication error is lower than that of medication management. It has also been observed that the techniques for the prevention of so called medication errors and its awareness are substandard to the awareness to medication error. A prompt continuous nursing programs and awareness programs are a mandate to decrease the medication errors.

:338-342.

8. Shara M Al.Factors contributing to medication errors in Jordan: A nursing prespective: Iranian Journal of Nursing and Midwifery Research.2011;16: 158-161.

9. Tang Fu-in et al. Nurses relate the contributing factors involved in medication errors: Journal of Clinical Nursing 2007;16: 447-57.

10. E. R. Seyyedeh, C. A. M ohammad, N. Amir, S. Amir, E. H. Ayeshe, N. M. Esmaeil, Medication errors of nurse in the emergency department: Journal of M edical ethics and history of medicine,2013;6.

11. Johari H, Shamsuddin F, Hussin N. M edication errors among Nurses in Government hospital :IOSR Journal of Nursing and Health Science.2013;1:18-23.

12. Shahrokhi A, Fbrahimpour F, Ghodousi A. Factors effective on medication errors: A nursing view: Journal of Research in Pharmacy Practice.2013;2:18-23.

13. Harding L, Petrick T. Nursing student medicstion errors: A retrospective review: Journal of Nursing Education.2008;47:43-47.

14. Olds DM, Clarke SP. The effect of work hours on adverse events and errors in health care: J ournal of Safety Research.2011;41:153-162. 
15. Dean GE, Scott LD, Rogers AE. Infants at risk: When nurse fatigue jeopardizes quality care: Advance Neonatal Care.2006;6:120-126.

16. Toruner EK, Uysal G.Cause, reporting and prevention of medication errors from a pediatric nurse perspective: Australian Journal of Advanced Nursing.;29:28-35.

17. Wright K. Student nurses need more than maths to improve their drug calculating skills: Nurse Education Today.2007;27:278-285.

18. Johnson J, Thomas M. M edication errors: Knowledge and attitude of Nurses in Ajman, UAE: Review of Progress.2013;1:1-6.

19. Grandell H N, Hupli M, Leinokilipi H. Finnish nurses and nursing students mathematical skills: Nurses Education Today.2006; 26:151161.

20. Fry MM, Daccy C. Factors contributing to incidents in medicine administration(Part-1): British Journal of Nursing.2007; 16:556-558.

21. A Shahrokhi, F Ebrahimpour, A Ghodousi. Factors effective on medication error: A nursing view: Journal of Research in Pharmacy Practice.2013;2:18-23.

22. Garrett $C$. The effect of nurse staffing patterns on medical errors and nurse burnout: AORN Journal.2008; 87:1191-1204

23. E. R. Seyyedeh, C. A. M ohammad, N. Amir, S. Amir, E. H. Ayeshe, N. M. Esmaeil, Medication errors of nurse in the emergency department: Journal of M edical ethics and history of medicine,2013;6.

24. A. Zayed, C. Sharon, C Imti, Medication errors in the Middle East countries: A systematic review of the literature: European Journal of Clinical Pharmacology, 2013,69;995-1008.

25. M. Eric, C. Eric, S. H. Thomas, Critical review: Medication errors in critical care, Critical care, 2008,12.

26. Shara M Al.Factors contributing to medication errors in Jordan: A nursing prespective: Iranian Journal of Nursing and Midwifery Research.2011;16: 158-161.

27. Tang Fu-in et al. Nurses relate the contributing factors involved in medication errors: Journal of Clinical Nursing.2007;16: 447-57.

28. E. R. Seyyedeh, C. A. M ohammad, N. Amir, S. Amir, E. H. Ayeshe, N. M. Esmaeil, Medication errors of nurse in the emergency department: J ournal of Medical ethics and history of medicine,2013;6.

29. Johari H, Shamsuddin F, Hussin N. Medication errors among Nurses in
Government hospital :IOSR Journal of Nursing and Health Science.2013;1:18-23.

30. Shahrokhi A, Fbrahimpour F, Ghodousi A. Factors effective on medication errors: A nursing view: Journal of Research in Pharmacy Practice.2013;2:18-23.

31. Harding L, Petrick T. Nursing student medicstion errors: A retrospective review: Journal of Nursing Education.2008;47:43-47.

32. Olds DM, Clarke SP. The effect of work hours on adverse events and errors in health care: Journal of Safety Research.2011;41:153-162.

33. Dean GE, Scott LD, Rogers AE. Infants at risk: When nurse fatigue jeopardizes quality care: Advance Neonatal Care.2006;6:120-126.

34. Toruner EK, Uysal G.Cause, reporting and prevention of medication errors from a pediatric nurse perspective: Australian Journal of Advanced Nursing.;29:28-35.

35. Wright K. Student nurses need more than maths to improve their drug calculating skills: Nurse Education Today.2007;27:278-285.

36. Johnson J, Thomas M. M edication errors: Knowledge and attitude of Nurses in Ajman, UAE: Review of Progress.2013;1:1-6.

37. Grandell H N, Hupli M, Leinokilipi H. Finnish nurses and nursing students mathematical skills: Nurses Education Today.2006; 26:151161.

38. Fry MM, Daccy C. Factors contributing to incidents in medicine administration(Part-1): British Journal of Nursing.2007; 16:556-558.

39. A Shahrokhi, F Ebrahimpour, A Ghodousi. Factors effective on medication error: A nursing view: Journal of Research in Pharmacy Practice.2013; 2:18-23.

40. Garrett $C$. The effect of nurse staffing patterns on medical errors and nurse burnout: AORN Journal.2008; 87:1191-1204.

41. E. R. Seyyedeh, C. A. M ohammad, N. Amir, S. Amir, E. H. Ayeshe, N. M. Esmaeil, Medication errors of nurse in the emergency department: Journal of Medical ethics and history of medicine,2013;6.

42. A. Zayed, C. Sharon, C Imti, Medication errors in the Middle East countries: A systematic review of the literature: European Journal of Clinical Pharmacology, 2013,69;995-1008.

43. M. Eric, C. Eric, S. H. Thomas, Critical review: Medication errors in critical care, Critical care, 2008,12. 